\section{Digestive \\ Diseases}

Avila, M.A. 524

Bartenschlager, R. 445

Bauer, J. 453

Berasain, C. 524

Bühler, S. 445

Chalaris, A. 492

Corrales, F.J. 524

Dooley, S. 514

Elizalde, M. 524

Foersch, S. 469

Garcia-Irigoyen, O. 524

Gautheron, J. 500

Greten, T.F. 477

Heikenwälder, M. 453
Korangy, F. 477

Latasa, M.U. 524

Luedde, T. 500

Matsuzaki, K. 514

Meindl-Beinker, N.M. 514

Moschen, A.R. 508

Namineni, S. 453

Neumann-Haefelin, C. 483

Neurath, M.F. 469

Nicou, A. 524

Perugorría, M.J. 524

Prieto, J. 524

Recio, J.A. 524

Reisinger, F. 453

Roderburg, C. 500

Rose-John, S. 492
Salis, F. 524

Schmidt, N. 483

Schmidt-Arras, D. 492

Thimme, R. 483

Tiegs, G. 443

Tilg, H. 508

Urtasun, R. 524

Waldner, M.J. 469

Wieser, V. 508

Yamamoto, K. 492

Yuan, D. 453

Zhao, F. 477

Zöller, J. 453

\title{
Subject Index Vol. 30, No. 5, 2012
}

ADAM17 524

Adipocytokines 508

Amphiregulin 524

Cancer 453, 477, 492, 508

Colitis-associated carcinoma 469

Colorectal cancer 469

Cytokine 453

Epidermal growth factor receptor 524

ER stress 445

Hepatitis C virus 445

Hepatocellular carcinoma 445, 483, 500, 514
IL-6 492

IL-6R 492

Immunotherapy 477,483

Inflammation 492, 500, 508

Inflammatory bowel disease 469

JNK 500

Liver 477

- cancer 445

- disease 514

Lymphotoxin 453

Mitogen-activated protein kinases 524

Mouse models 500
NF- $\mathrm{B} 500$

p38 $\alpha 500$

Protein methylation 524

Shedding 492

Soluble receptor 492

Steatosis 445

TGF- $\beta 514$

Tolerance 477

Trans-signaling 492

Tumor immunology 483

- necrosis factor 500

(C) 2012 S. Karger AG, Basel 